\title{
Do you think I should be scared? The effect of peer discussion on children's fears
}

Article

Accepted Version

Creative Commons: Attribution-Noncommercial-No Derivative Works 4.0

Ooi, J., Dodd, H. F., Stuijfzand, B. G., Walsh, J. and Broeren, S. (2016) Do you think I should be scared? The effect of peer discussion on children's fears. Behaviour Research and Therapy, 87. pp. 23-33. ISSN 0005-7967 doi: https://doi.org/10.1016/j.brat.2016.08.009 Available at https://centaur.reading.ac.uk/66558/

It is advisable to refer to the publisher's version if you intend to cite from the work. See Guidance on citing.

Published version at: http://www.sciencedirect.com/science/article/pii/S0005796716301401

To link to this article DOI: http://dx.doi.org/10.1016/j.brat.2016.08.009

Publisher: Elsevier

All outputs in CentAUR are protected by Intellectual Property Rights law, including copyright law. Copyright and IPR is retained by the creators or other copyright holders. Terms and conditions for use of this material are defined in the End User Agreement.

www.reading.ac.uk/centaur 
Central Archive at the University of Reading

Reading's research outputs online 
This is the authors' version of the accepted manuscript:

Ooi, J., Dodd*, H.F., Stuijfzand, B.G., Walsh, J., Broeren, S. (2016). Do you think I should be scared? The effect of peer discussion on children's fears. Behaviour Research and Therapy, 87, 23-33. doi:10.1016/j.brat.2016.08.009.

(C) 2016. This manuscript version is made available under the CC-BY-NC-ND 4.0 license http://creativecommons.org/licenses/by-nc-nd/4.0/

* Corresponding author.

E-mail address: h.f.dodd@reading.ac.uk 


\begin{abstract}
This study investigated whether close friends affect each other's fear responses (fear beliefs and avoidance) when they discuss fear-related issues together. Children $(N=242)$ aged 7 to 10 years were first presented with ambiguous and threatening information about two novel animals respectively, after which their fear responses towards each animal were assessed (T1). Next, dyads of close friends had a discussion about their feelings regarding the animals, and their fear responses were measured again (T2). Results showed that children influenced each other's cognitions following the discussion; from T1 to T2 their fear responses became more similar and close friends' fear responses at T1 significantly predicted children's fear responses at T2. Gender pair type predicted change in children's fear responses over time. Children in boy-boy pairs showed a significant increase in fear responses following the discussion; their fear level became more in line with that of other gender pairs at T2, while those in girl-girl pairs showed a significant decrease in their fear beliefs, at least when threatening information was given. Differences in anxiety level between close friends did not affect change in fear responses over time. Altogether, the results indicate that children may affect each other's fears.
\end{abstract}

Keywords: fear, anxiety, close friends, children, peer influence 


\section{Introduction}

Fears are highly prevalent in childhood, and are usually mild and benign (Gullone, 2000). According to Lang's $(1968,1985)$ tripartite model, fear is characterized by verbal-cognitive responses (e.g. subjective feelings of apprehension), behavioural changes (e.g. avoidance), and physiological arousal (e.g. sweating, trembling, heart palpitations). Normative fears include fear of ghosts and the supernatural in early childhood (Bauer, 1976), fear of animals in middle childhood, and fear of selfinjury as well as socio-evaluative apprehension in late childhood and adolescence (Muris \& Field, 2010). Although these fears usually diminish over time, a substantial minority of children go on to develop significant fears that interfere with their daily functioning. Specific phobias are the most common form of childhood anxiety disorders (Costello, Egger, Copeland, Erkanli, \& Angold, 2011). If left untreated, phobias can continue into adulthood; retrospective interviews with phobic adults indicate that certain fears, such as animal phobias, first developed when the individuals were as young as 7 years old (Öst, 1987).

In exploring the origins of fears and phobias, research in behavioural genetics suggests that up to half of the variance in childhood fears can be explained by a child's genetic inheritance, depending on the type of fear (Eley \& Gregory, 2004). This leaves a substantial role for environmental factors, such as discrete learning experiences. Rachman (1977) posited that the transmission of verbal threat information is one of the pathways through which children learn fears and phobias. In keeping with this hypothesis, a substantial body of research has demonstrated that children generally become less fearful of stimuli when presented with positive information about the stimulus and more fearful when presented with threatening information (Muris \& Field, 2010). For instance, Field et al. (2001) presented either threatening or positive information about a novel monster doll to children aged 7-9 years, and measured their fear beliefs about the doll before and after being given the information. Results showed that children's fear beliefs towards the monster doll increased following threatening information and decreased following positive information. More 
recent research suggests that ambiguous information also heightens children's fears, although the observed effect is weaker relative to threatening information (Dalrymple-Alford \& Salmon, 2013; Field \& Field, 2013; Muris, Rassin, et al., 2009).

Overall, there is considerable evidence showing that children's fears are affected by the information they are given from others. Children may receive this information from a variety of sources, including parents and peers (Muris \& Field, 2010). Research examining the intergenerational transmission of anxiety has provided some indication that parents may inadvertently transmit anxiety-related cognitions to their children (Drake \& Ginsburg, 2012; Hadwin et al., 2006). There is evidence that children share similar patterns of interpretation bias (a tendency to interpret ambiguity negatively) with their parents (Bögels et al., 2003; Creswell \& O'Connor, 2006; Creswell et al., 2005; Creswell, Shildrick, et al., 2011), although other studies have failed to find this association (Creswell et al., 2006; Gifford, Reynolds, Bell, \& Wilson, 2008). Verbal information transfer is one of the plausible pathways through which this intergenerational transmission of anxious cognitions occurs (Field \& Lester, 2010; Hadwin et al., 2006; Muris \& Field, 2010; Ooi, Dodd, \& Walsh, 2015). For example, Ooi, Dodd and Walsh (2015) found an association between the amount of threat parents included in stories for their children and the way their children completed their own stories.

Further indication that parents can affect children's anxiety-related cognitions comes from early research demonstrating that parents enhance their children's interpretation bias and/or avoidant responses following family discussions (Barrett, Rapee, Dadds, \& Ryan, 1996; Chorpita \& Albano, 1996; Dadds, Barrett, Rapee, \& Ryan, 1996). For instance, Barrett et al., (1996) and Dadds et al. (1996) found that clinically anxious children became more avoidant following family discussion of ambiguous scenarios, with their parents exhibiting a tendency to agree with their avoidant plans. In contrast, non-anxious children became more prosocial following the discussion, with their parents exhibiting a tendency to listen to and agree with their prosocial plans. 
It is plausible that the transmission of fears, as well as ideas about how to behave in fearprovoking situations, might also occur in other close relationships. As children transition from early to middle childhood, peers become increasingly influential as a supplementary source of information about the environment alongside parents (Schunk, 1987; Schunk \& Hanson, 1985). Therefore, it is possible that children in close friendships might affect each other's fears. Thus far, however, there has been relatively little research in this area. To our knowledge, only Muris and Rijkee (2011) have explored whether children's fears are influenced by their interactions with other children of the same age, although the children were deliberately paired with a non-close peer for the purpose of their study. To examine this, half the children (aged 9-12 years) were first exposed to positive information about a novel animal, after which their fear beliefs towards the animal were measured. Subsequently, the children were exposed to ambiguous information about another novel animal, followed by a discussion about fear-related issues with a same-gender peer before their fear beliefs towards the animal were measured. The same procedure was adopted for the other half of the children in the study, but they were first exposed to ambiguous information in the individual (nondiscussion) condition, followed by the presentation of positive information in the peer-discussion condition. Results showed that when presented with positive information, all children who had a peer discussion were less fearful towards the animal, compared to those in the individual condition. When presented with ambiguous information, boys who had a discussion with a peer had lower fear beliefs than those who did not have the discussion (individual condition). However, there was no significant difference between the fear beliefs of girls in either the discussion or non-discussion conditions. As a whole, these findings indicate that discussing ambiguous information with a nonclose peer might lead to an attenuation of fear beliefs for boys. Muris and Rijkee posited that this could be influenced by children's gender-role orientation, with boys downplaying their level of fearfulness when discussing their fears with other boys they are not close to, while the expression of fear may be more accepted among girls.

To extend current understanding about how peers might affect each other's fears during 
childhood, there are a number of areas to be explored. First, as close friends tend to interact more regularly with each other than non-close peers, children in close friendships may play an influential role in affecting and/or maintaining each other's fears. To understand the origins of children's fears and to potentially reduce these fears, it is more ecologically valid to examine the interaction between close friends than non-close peers. Second, it is not clear how close friends affect each other's fear beliefs when they are given threatening information (note that Muris and Rijkee gave only ambiguous and positive information) and enter a discussion situation with relatively high fear beliefs. This is important as it reflects many real-life scenarios when children may be feeling fearful, such as exams. It is possible that the same attenuating effect will be found in the context of threatening information but also possible that children may enhance each other's fears in this context.

A further consideration is the potential effect of individual differences in the transmission of fears within close friendships. It is plausible that the anxiety level of the two individuals involved in the discussion may determine the effect of the discussion on their fear beliefs; when children discuss ambiguous information with a less anxious friend, they may adjust their beliefs and become less fearful. Similarly, when children discuss ambiguous information with a more anxious friend, they may adjust their beliefs and become more fearful. This has yet to be explored in relation to anxiety but research examining aggression found that adolescents who communicated with online peers (econfederates) who endorsed hostile intent to others reported increased hostile attributions themselves following the interaction, while those exposed to the benign intent condition reported reduced hostility (Freeman, Hadwin, \& Halligan, 2011).

The present research aimed to significantly extend the existing literature regarding peer discussion of fear by exploring how close friends affect each other's fear responses when they discuss fear-related issues together. Besides children's fear beliefs, the present study also explored whether their avoidance behaviours were affected by the discussion. Research of this nature has the 
potential to inform our understanding of the development and/or maintenance of childhood anxiety as well as practical applications. For example, it is important for school-based interventions aimed at the prevention and/or treatment of anxiety such as the FRIENDS for Life program (Barrett, 2005) and group-based therapy to understand what the likely outcome of peer discussion of fears might be and therefore whether it is likely to be useful or detrimental as a therapeutic tool. Furthermore, if research shows that peers can affect each other's fear beliefs and avoidance behaviours, it may be possible to include peers in a targeted intervention to change cognitions using an approach similar to cognitive bias modification (cf. Lau, Pettit, \& Creswell, 2013).

In the present study, children were first presented with ambiguous and threatening information about novel animals, after which their fear beliefs and behavioural avoidance (together referred to as fear responses) for each animal were measured (T1). Subsequently, pairs of close friends discussed their fear beliefs and avoidance before completing the measures again independently (T2). The hypotheses evaluated for the present research were as follows. Replicating the findings of previous verbal information transfer research, it was hypothesised that, $(\mathrm{H} 1)$ children will exhibit significantly higher fear responses towards the animal described as threatening, compared to the animal described as ambiguous. Additionally, following research on shared cognition in other close relationships (e.g. parents and children), it was further hypothesised that close friends will share similar patterns of fear responses at baseline. Therefore, $(\mathrm{H} 2)$ the fear responses of close friends will be significantly correlated at T1. Next, it was hypothesised that close friends will influence each other's fear responses after the discussion. Specifically, we hypothesised that $(\mathrm{H} 3 \mathrm{a})$ the correlation between the fear responses of close friends will be significantly stronger at $\mathrm{T} 2$ than at $\mathrm{T} 1$, and that (H3b) children's fear responses after the discussion will be predicted not only by their own fear responses at $\mathrm{T} 1$, but also by their friends' fear responses at $\mathrm{T} 1$. The interaction between own and friend's T1 fear responses on T2 fear responses will also be explored to examine whether the relationship between own fear responses at $\mathrm{T} 1$ and $\mathrm{T} 2$ is moderated by friend $\mathrm{T} 1$ fear responses. Next, we were interested to examine whether the effect of the peer discussion varied across gender 
pairs (boy-boy, girl-girl, boy-girl). Based on the findings of Muris and Rijkee (2011), we hypothesised that when presented with a mbiguous information, $(\mathrm{H} 4)$ only children in boy-boy pairs will show a significant decrease in fear responses following peer discussion, with other gender pairs showing no significant change. There is no previous research from which to form a hypothesis regarding how the effect of the discussion may vary across gender pairs following the presentation of threatening information so this analysis was exploratory. Lastly, we were also interested to explore whether the effects of peer discussion were moderated by differences in anxiety levels between close friends. Again, this analysis was exploratory as there is no previous research on which to base a hypothesis.

\section{Method}

\subsection{Participants}

Two hundred and forty two children (106 boys, 136 girls) aged between 7 and 10 years ( $M=$ $9.24, S D=.94)$ were recruited from a primary school in Norfolk, UK. Class teachers put children into pairs based on those who were close friends with each other. In order to capture genuine close friendships, we did not restrict friendship pairs to same-sex pairs. This resulted in 40 pairs of boys, 55 pairs of girls, and 26 boy-girl pairs. Children were invited to take part in the study initially via a letter sent home to parents explaining the details of the research. Parents who did not want their children to take part notified the school directly. The School of Psychology Research Ethics Committee at the University of East Anglia approved all the methods of this study, including the use of opt-out parental consent. This method of consent was adopted to maximise the chances of close friendship pairs participating in the study together and was the method of consent preferred by the school for reasons of inclusion. Nevertheless, we ensured that parents were fully informed about the study (via an information sheet and reminder letter a week later), and had the opportunity to optout (testing began a week after the deadline to opt-out). All children in Years 3,4 and $5(n=288)$ were invited to participate and the parents of seven children withdrew them from the study. The remaining 281 children were invited to take part during school time. Their class teacher explained the research to them and they were informed that they did not have to take part if they did not 
want to. The class teacher gave this information to ensure that they did not feel pressured by the researcher to agree to participate. A further 39 children did not complete the research for the following reasons: absent from school $(n=26)$, did not consent $(n=1)$, teacher stated that, due to a language or behaviour problem, the child was not able to join a mainstream class without support (n $=12)$. The majority of participants were white British (69.8\%), while the remaining identified as Portuguese (9.9\%), white European (5.8\%), other white backgrounds (4.5\%), other mixed background (2.5\%), white and black Caribbean (2.5\%), other black African (1.2\%), and Asian (0.8\%). Additionally, $31.8 \%$ of the total sample were eligible for and claiming free school meals (indicative of lower income families), compared to $18.3 \%$ of primary school pupils in England (Department for Education, 2013).

\subsection{Measures}

\subsubsection{Anxiety Symptoms}

Children completed the Spence Children's Anxiety Scale (SCAS; Spence, 1998), which is a 45-item self-report measure assessing the severity of anxiety symptoms in children, in accordance with anxiety disorder dimensions as defined by the DSM-IV. The SCAS has been used with children aged 7-12 years (Gifford et al., 2008; Kelly, Barker, Field, Wilson \& Reynolds, 2010; Spence, 1998) and has strong internal consistency and good test-retest reliability (Spence, 1997). Cronbach's $\alpha$ in this sample was .91.

\subsubsection{Fear Beliefs}

Children completed the Fear Beliefs Questionnaire, (FBQ; Field et al., 2001) as used by Muris and Rijkee (2011), which is a 10-item measure assessing their fear beliefs about each novel animal. The FBQ has been used with children aged 6-9 years (Field \& Lawson, 2003) and 9-12 years (Muris \& Rijkee, 2011), and has moderate to good internal consistency (Field, 2006). Cronbach's alphas in this sample were between .91 and .94 . 


\subsubsection{Pictures and Stories}

Pictures of two Australian marsupials (the Cuscus and the Quoll) were used to introduce the animals to the children. As children in Britain are unfamiliar with these marsupials, it is likely that they do not possess any prior knowledge about these novel animals. The children were read two versions of information about the animals - ambiguous and threatening (Muris, Rassin, et al., 2009), which were presented counterbalanced with the animal type.

\subsubsection{Behavioural Avoidance Task}

The Nature Reserve Map (NRM) (refer to Appendix A) was designed to provide a behavioural measure of children's fears towards novel animals. This map is an adaptation of Field and StorksenCoulson's (2007) 3D model of the Nature Reserve Task, which enables the measurement of avoidance behaviours in a questionnaire format (A4-sized). The map shows an enclosure with fences on the top and bottom edges. A straight horizontal path is positioned in the middle, with bushes and flowers evenly distributed on both sides. The Cuscus or Quoll is situated in a bush at one end of the path, while the other end is an opening to the enclosure. There is a Nature Reserve Map for each animal (The Cuscus Nature Reserve Map and The Quoll Nature Reserve Map), with the opening to the enclosure counterbalanced to appear on either the left- or right-end of the page. The children were told that the Nature Reserve Map shows where the animal lives, and were asked to draw a cross on the path to indicate where they would like to be in the nature reserve. Avoidance behaviour was measured as the distance $(\mathrm{cm})$ from the indicated cross to the animal.

\subsection{Procedure}

The research was conducted in school, one class at a time. At baseline (T1), the children first completed measures of anxiety symptoms. Their class teacher then read out ambiguous information about animal $A$, after which they completed the FBQ and NRM for animal $A$. Next, the children were presented with threatening information about animal $B$, followed by the completion of the 
corresponding FBQ and NRM. The children were instructed to complete the measures on their own, without discussing their answers with each other. Teachers were asked to give this information as we felt that the children's familiarity with their teacher would help them to attend to and understand the information they were being given; teachers were provided with a script to follow to ensure the information they gave was standardised. Questionnaire packs were counterbalanced by class; the assignment of animal (Cuscus vs. Quoll) to the type of information (ambiguous vs. threatening), and the position of the opening of the enclosure on the map (left vs. right) were counterbalanced. In efforts to minimize any potential carry-over effects, ambiguous information about an animal was always presented first, followed by threatening information about the other animal.

The discussion and post-test (T2) were conducted after a 15-minute break. At this time, class teachers paired the children based on their close friendships with each other - determined by the friend they chose as a partner on school outings. The children were taken out of class one pair at a time. Each pair was seen in a separate room by either the first author or one of two female research assistants, trained by the first author. At the beginning of each discussion session, the experimenter first reminded the children about Animal A and presented the ambiguous information to them again, after which they were instructed to explicitly discuss with each other their answers for the FBQ and Nature Reserve Map, without referring to their answers for the questionnaires they previously completed at $\mathrm{T} 1$. To guide the discussion, the experimenters read out the questions on the FBQ and NRM, followed by a further prompt to elicit the reasoning for their answers (e.g., Would you find it scary to touch a Cuscus? Explain why you would/would not find it scary). The children took turns to answer each question in a counterbalanced manner (e.g., child $\mathrm{X}$ was asked to respond to a question first, followed by child $Y$. For the next question, child $Y$ was asked to respond first, followed by child X). The children were encouraged to discuss and elaborate on their answers with each other. They were then separated and asked to complete both the FBQ and NRM measures again on their own. The same procedure was then repeated for Animal B, with the presentation of 
threatening information, followed by the discussion and completion of the measures. The discussion for each animal took approximately 10 minutes to complete. After all the pairs had taken part in the discussion and completed their measures for a second time, the children were debriefed as a class. During debrief, they were then presented with real information about the Cuscus and the Quoll, shown a short video of each animal, and a plush toy version of each animal was passed around the class for the children to stroke. Finally, the children were thanked for their participation and given a small gift. Figure 1 provides a schematic overview of the procedure of the present study.

\section{Results}

\subsection{Data Preparation}

None of the variables described above were normally distributed, except for children's ambiguous FBQ at T1 and T2. There was a slight positive skew in SCAS scores and normality was observed when a square root transformation was used. The square root transformed SCAS variable was used in the preliminary analyses as well as the mixed ANCOVA analyses, while the nontransformed SCAS variable was used in the multilevel analyses. For the remaining variables that were not normally distributed, transformations did not amend the normality of the distribution of responses. Field (2013) recommends using bootstrapping for analyses involving data that violates the assumption of normality. Therefore, all correlational analyses involving these non-normally distributed variables were bootstrapped, and estimates using 1000 bootstrapped samples are reported. For the multilevel analyses, restricted maximum likelihood estimation was used.

\subsection{Analyses}

\subsubsection{Preliminary Analyses}

Preliminary analyses indicated no significant effects of animal type (Cuscus vs. Quoll) on children's fear beliefs and avoidance at both T1 and T2 for ambiguous information ( $p s>.15$ ) or threat information ( $p s>.10)$. Similarly, there were no significant effects of the position of the NRM 
enclosure opening (left vs. right) on children's behavioural avoidance ratings at both T1 and T2 for threat information ( $p s>.50$ ). For ambiguous information, children indicated significantly greater avoidance of the animals when the enclosure opening was on the right of the NRM, compared to when it was on the left at both T1 and T2, $t(227.62)=4.03, p<.001, d=.26 ; t(224.17)=4.80, p$ $<.001, d=.31$. Two sets of analyses involving both these variables were conducted, first involving the group of children exposed to the left NRM opening, followed by the other group exposed to the right opening. Findings from both sets of analyses were comparable, so the effect of the enclosure opening position on ambiguous information is not controlled for in the analyses reported.

There were significant positive correlations ( $r$ range $=.14-.55, p s<.05$ ) between anxiety symptoms and fear responses (fear beliefs and avoidance behaviours) when ambiguous and threatening information was presented to the children at T1 and T2. Girls $(M=43.62, S D=19.82)$ reported significantly higher anxiety symptoms than boys $(M=29.85, S D=18.10), t(239)=2.55, p=$ $.01, d=.33$. There was no significant relationship between children's age and their anxiety symptoms, $r=-.03, p=.67$. Additionally, girls reported significantly higher fear beliefs and avoidance behaviours than boys when ambiguous and threatening information was presented to them at $\mathrm{T} 1, \mathrm{ps}$ $<.002$. At $\mathrm{T} 2$, there were no significant gender difference in children's reported fear beliefs when they were presented with either information types, $p s>.22$. However, girls reported significantly greater avoidance than boys when ambiguous and threatening information was presented to them at T2, ps <.04. Moreover, although children's age was not significantly correlated with their fear beliefs across information types at $\mathrm{T} 1, p s>.08$, there was a significant negative correlation between age and behavioural avoidance across information types, $p s<.04$. At T2, although age was not significantly correlated with fear beliefs across information types, or with behavioural avoidance when ambiguous information was presented to them, $p s>.05$, there was a significant negative correlation between age and behavioural avoidance when threatening information was presented to them, $p=.02$. 


\subsubsection{Verbal Information Transfer (Manipulation Check)}

[INSERT TABLE 1 HERE]

Table 1 shows the descriptive statistics for children's fear beliefs and behavioural avoidance at $\mathrm{T} 1$ when ambiguous and threatening information was presented to them. To explore the effects of verbal information on children's fear beliefs and behavioural avoidance, two 2 (Information Type: Ambiguous or Threatening) $\times 2$ (Gender) mixed ANCOVA analyses were conducted, with information type as the repeated measures variable, as well as anxiety symptoms and age as covariates. The effects of anxiety symptoms, gender and age were controlled for in the analyses above because preliminary analyses showed that these variables were related to fear beliefs and/or behavioural avoidance at $\mathrm{T} 1$. The results are presented in Table 2 below.

\section{[INSERT TABLE 2 HERE]}

It was hypothesised that children would exhibit significantly higher fear responses towards the animal described as threatening, compared to the animal described as ambiguous ( $\mathrm{H} 1)$. Consistent with this hypothesis, for fear beliefs, results showed a significant main effect of information type. In addition, children's anxiety symptoms interacted with information type. As shown in Figure 2, anxiety symptoms had a greater effect on children's fear beliefs towards the animal described as ambiguous compared to when the animal was described as threatening. Finally, there was no evidence for a main effect of information type for behavioural avoidance.

[INSERT FIGURE 2 HERE]

\subsubsection{Effects of Peer Discussion}

To examine whether close friends shared similar patterns of fear responses at baseline $(\mathrm{H} 2)$, and whether their fear responses became more similar after the discussion $(\mathrm{H} 3 \mathrm{a})$, bootstrapped bivariate correlations were first conducted to explore the relationship between fear responses in close friendship pairs at baseline (T1) and at post-test (T2). Next, Z Statistics were used to compare 
the correlations between children's fear responses at baseline and at post-test. Table 3 shows that close friends' fear beliefs, as well as their behavioural avoidance at T1 were significantly correlated, indicating that close friends do share similar patterns of fear responses towards both the animals described as ambiguous and threatening at baseline. Moreover, the relationship between close friends' fear beliefs and avoidance behaviours became significantly stronger from $\mathrm{T} 1$ to $\mathrm{T} 2$, suggesting that children's fear responses towards both the animals described as ambiguous and threatening became more similar following the discussion.

\section{[INSERT TABLE 3 HERE]}

Next, we examined whether children's own fear responses at T1, as well as their friends' fear responses at T1 predicts children's fear responses at T2 (H3b). We also explored whether own and friends' T1 fear responses might interact to predict T2 responses. Regression analyses were conducted to explore the individual effects of each child at T1 (child's own fear responses at T1, friend's fear responses at T1, child's own quadratic fear responses at T1, and friend's quadratic fear responses at T1), as well as their interaction (child's own fear responses at T1 $\mathrm{x}$ friend's fear responses at T1), on the child's fear responses at T2. Including the interaction, combined with the quadratic effects is in keeping with the approach described in Laird and Weems (2011) and Laird and De Los Reyes (2013), and allows examination of whether, for example, the effect of peer discussion varies according to the child's own initial fear responses and whether this is moderated by their friend's initial fear responses. Due to the correlated fear responses within each dyad, as evidenced in Table 3, ordinary regression analyses are inappropriate. Instead, a multilevel model with random intercepts was specified where fear responses on T2 were nested within dyads, following Kenny, Kashy, and Cook (2006). This was repeated for each of the four response variables (i.e. fear beliefs and behavioural avoidance for both ambiguous and threatening animals). Results are reported in Table 4. Except for avoidance in the threat information condition, fear responses of both members of a dyad at T1 were positive predictors for the child's fear response at T2, indicating that the higher 
the fear response at T1 for either member, the higher the fear response was at T2. For avoidance in the threat information condition, this was not the case for the friend's fear response at T1. Here however, the interaction between both members' T1 response was significant. Inspection of the interaction plot in Figure 3 shows a steeper slope for children paired with a friend showing high initial threat avoidance (+ 1 SD), than for children paired with a friend showing low initial threat avoidance (-1 SD). This indicates that, although threat avoidance generally increased from T1 to T2, this increase was most pronounced when a child's friend had a high T1 score.

[INSERT TABLE 4 HERE]

[INSERT FIGURE 3 HERE]

Table 5 shows the descriptive statistics for children's fear responses towards novel animals at both $\mathrm{T} 1$ and $\mathrm{T} 2$ when ambiguous and threatening information were presented to them.

\section{[INSERT TABLE 5 HERE]}

To explore whether gender pair type (H4) and the difference between close friends' anxiety levels affect change in children's fear beliefs and behavioural avoidance from T1 to T2, a regression analysis was conducted for each of the four response variables (i.e. fear beliefs and behavioural avoidance for both ambiguous and threatening animals). The dyadic nature of the data, as well as the fear responses being measured at $\mathrm{T} 1$ as well as $\mathrm{T} 2$ suggests that observations are not independent. As such, a multilevel model with random intercepts was specified following Kenny et al. (2006), nesting fear responses at T1 and T2 within a child, which was subsequently nested within a dyad. T2 was added to the model as a dummy variable, T1 being the reference category. In addition for gender-pairs, Boy-Girl, and Girl-Girl were added as dummy variables, defining Boy-Boy as the reference category. To investigate effects of different levels of anxiety within a dyad, an interaction effect analysis was conducted as described in Laird and De Los Reyes (2013). A significant 
anxiety interaction effect would indicate that the pattern of anxiety between the members of a dyad (e.g. both low, both high, one low, one high etc.) would affect fear responses at T1 differently. More importantly, an interaction of this 'anxiety interaction' term with T2 would indicate that change from T1 to T2 varied according to these dyads' anxiety patterns.

Results of the multilevel analyses are reported in Table 6 . The results that are relevant to the research questions of the present study are highlighted. It was hypothesised that change in children's fear responses from T1 to T2 may be affected by gender pair type (H4) as well as the difference in anxiety levels between close friends. It is important to note that, as T1 and Boy-Boy were the reference categories, the main effect of $\mathrm{T} 2$ should be interpreted as the change in children's responses from T1 to T2 in a boy-boy dyad. The main effect of T2 indicated that children in boy-boy pairs showed a significant increase in fear beliefs towards the animal described as ambiguous and in avoidance of the animal described as threatening. Further there was a significant decrease in the fear beliefs of girl-girl pairs in the threat information condition. No other effects of gender pairs were observed. Finally, there were no significant interactions between time and anxiety in predicting children's fear beliefs and/or behavioural avoidance, indicating that differences between children's anxiety levels at T1 did not moderate change from T1 to T2.

\section{[INSERT TABLE 6 HERE]}

\section{Discussion}

There is some existing evidence that children in middle childhood affect each other's fears during peer discussion (Muris \& Rijkee, 2011). The present study is the first to examine whether close friends respond to verbal information about novel stimuli in a similar way to one another and how they affect each other's fears during discussion.

First, this study examined how children's fear beliefs and avoidance behaviours regarding novel animals were affected by the threatening and ambiguous information given to them. The 
results were consistent with the first hypothesis; children reported significantly higher fear beliefs when they were given threatening information about the animal than they did when given ambiguous information. This effect was not observed for avoidance behaviours. Children who were more anxious had higher fear beliefs in both conditions, with the effect of anxiety particularly pronounced in the ambiguous information condition. This finding was expected given the literature on interpretation bias, in which children with higher levels of anxiety tend to interpret ambiguous stimuli as more threatening than children with lower levels of anxiety (Creswell et al., 2005; Dodd, Stuijfzand, Morris \& Hudson, 2015; Hadwin et al., 1997).

The primary focus of the present study was whether, after being given the information about the novel animals, close friends shared similar patterns of fear beliefs and avoidance, and how they affected each other's responses following a discussion. The results showed that children in close friendships shared similar patterns of fear beliefs and avoidance, even before they had discussed their responses ( $\mathrm{H} 2$ ). Additionally, evidence suggested that close friends influenced each other's anxious cognitions following the discussion. That is, in both the ambiguous and threat information conditions, children's fear beliefs and avoidance following the discussion were significantly more similar than at pre-test (H3a). Results from the multilevel analyses provided further insight into the transmission of anxious cognitions between close friends. In both the ambiguous and threatening information conditions, children's fear responses at $\mathrm{T} 2$ were influenced not only by their own initial fear responses, but also by how fearful and avoidant their friend was at T1. As such, regardless of a child's own fearfulness at T1, he/she is likely to become more fearful after a discussion with a highly fearful friend and less fearful after a discussion with a friend with low T1 fear. However, this was not true for children's avoidance when given threatening information; their threatening avoidance at T2 was not influenced by their friend's initial avoidance, but instead there was a significant interaction between own and friend's T1 avoidance. There was a general trend for an increase in avoidance from T1 to T2 but children with a highly avoidant friend at T1 showed a greater increase in avoidance at $\mathrm{T} 2$ when compared to those who had a less avoidant 
friend at $\mathrm{T} 1(\mathrm{H} 3 \mathrm{~b})$. These results show for the first time that children in close friendships do exhibit shared patterns of fear-related cognitions, and that they influenced each other's fears during the discussion, either directly or by moderating change. Whilst this is the first study to examine fearrelated cognitions in close friends, the findings are in keeping with previous research among parentchild pairs which showed that parents and their children shared similar patterns of interpretation bias (Bögels et al., 2003; Creswell \& O'Connor, 2006; Creswell et al., 2005; Creswell, Shildrick, et al., 2011), and that family discussions of ambiguous scenarios affected children's interpretation bias and/or avoidant responses (Barrett et al., 1996; Chorpita \& Albano, 1996; Dadds et al., 1996).

The present study hypothesised two factors that may affect children's change in fear beliefs and avoidance from T1 to T2: the gender pair type and the difference between close friends' levels of anxiety. The results for each of these moderators will be discussed in turn. First, results revealed that only children in boy-boy pairs and girl-girl pairs showed statistically significant change from T1 to T2. Specifically, children in boy-boy pairs reported higher fear beliefs at T2 than at T1 for the animal described as ambiguous. This fear accentuating effect was not significant when boys were given threatening information, but the direction of effect was the same. Data exploration using scatter plots of the threatening fear beliefs variables at T1 and T2 showed clustering of data points towards the high scores of the FBQ scale for all gender pair types. This indicates that ceiling effects probably affected the result for threatening information. Additionally, boy-boy pairs showed an increase in avoidance following the discussion for both information types but this was only statistically significant for threatening information. Next, children in girl-girl pairs reported significantly lower fear beliefs at T2 than at T1 for the animal described as threatening. This fear attenuating effect was not significant when girls were given ambiguous information, although the direction of the effect was the same. In contrast, girl-girl pairs showed an increase in avoidance following the discussion for both ambiguous and threatening information, but this was not statistically significant for either information type. These findings are not consistent with the fourth hypothesis: based on findings from previous research (Muris \& Rijkee, 2011), we predicted that only 
boy-boy pairs would show significant change in their fear beliefs and avoidance following the discussion. This was partially supported, but we expected that boys would become less fearful, not more fearful, and that girls would remain comparatively fearful, not become less fearful.

Close examination of the mean values shown in Table 5 indicates that relative to the other gender pairs, boy-boy pairs reported unusually low levels of fear beliefs and avoidance at T1. Following the discussion, their levels of fear beliefs and avoidance came to resemble those of children in the other gender pairs at T2. This is important because it highlights that children in boyboy pairs were not becoming particularly fearful of these animals following the discussion, but were instead reporting levels of fear and avoidance that are typical of other children their age in this sample.

It is unclear why an unexpected direction of change was observed in the fear responses of same sex pairs. Previous research (Ollendick, Yang, Dong, Xia, \& Lin, 1995) has demonstrated that children perceive their patterns (number, content and intensity) of fears as similar to their best friends', but dissimilar to other classmates. More specifically, boys perceived other boys as more fearful than themselves or their best friends, while girls perceived other girls to be less fearful than themselves or their best friends. When this finding is considered within the context of research on gender role orientation, which has shown that fear and anxiety are negatively associated with masculinity and positively associated with femininity (Ginsburg \& Silverman, 2000; Palapattu, Kingery, \& Ginsburg, 2006; Muris, Meesters, \& Knoops, 2005), it seems plausible that boys may have underreported their actual levels of fear beliefs initially, to maintain the image that they are less fearful than other boys. After the discussion with their close friend, and learning that their close friend was also fearful of the animals, they may have felt more confident about reporting their actual level of fearfulness. In line with this idea, the difference in findings between the present study and the results reported by Muris and Rijkee (2011) could be explained by the friendship status in pairs of children; in Muris and Rijkee's (2011) study, boys discussed with non-close peers and so may 
have continued to maintain the 'less fearful than others' image during the discussion. If both parties adopted this approach, one would expect boys who had a discussion to report lower levels of fears than those who did not have a discussion, as observed by Muris and Rijkee (2011). Following similar reasoning, girls may have initially presented themselves in a manner consistent with a feminine gender role orientation (more fearful) and adjusted this downward after discussing with a close friend. That said, this reasoning is inconsistent with Muris and Rijkee's (2011) findings that showed comparable fear levels in girls who had a discussion with a non-close peer and those who did not have a discussion. This explanation is of course very tentative; replication and further exploration of these ideas is required. For example, in future work it would be useful to assess children's gender role orientation as well as their gender to examine how this affects initial responses and change following discussion.

We were also interested in whether the difference between friends' anxiety levels affected the transmission of fears. The results provided no evidence to support this idea; change in children's fear beliefs and behavioural avoidance following the discussion was not moderated by how discrepant the anxiety scores were between individuals in peer pairs. That is, children were affected equally by the discussion regardless of whether their friend was more or less anxious than they were. This finding is somewhat in keeping with previous research on depression, which has shown that young adults affect each other's cognitive vulnerability (ruminative responses and hopelessness) after cohabiting as roommates for only three months, but these changes were not influenced either by the participants' or roommates' level of depressive symptoms (Haeffel \& Hames, 2014). This is an important finding as it shows that having a close friend who is more anxious may not necessarily have a negative impact on the child's own anxious cognitions. However, it also indicates that having a friend who is less anxious does not reduce the fear beliefs and avoidant strategies of children who are more anxious. Therefore, having anxious children discuss their fears with friends who are less anxious is, in itself, unlikely to have a significant benefit for the anxious child. 
There are some limitations with the present research and the results should be interpreted with these in mind. For instance, the present study adopted a repeated measures design to measure possible change in children's fear responses across time when presented with different types of information. However, we did not include a non-discussion control group, which would allow us to determine whether it was the discussion per se that influenced the change in children's fear responses, or whether the change could be due to practice effects. As is the case with other similar research, another limitation of this study is the reliance on self-report measures only. To minimize possible social desirability issues, future research could adopt the implicit association task (IAT) to measure children's implicit attitudes towards the novel animals, as well as the behavioural approach task using touch boxes as a direct measure of behavioural response (see Field \& Lawson, 2003; Field, Lawson \& Banerjee, 2008). Additionally, in the present study, close friendship pairs were nominated by class teachers. There are some advantages to this method over peer-nomination: it is faster; it avoids a situation where a child is distressed by not having been chosen as a 'best friend'; teachers may be better able to comment on the closeness of friendships over the long-term whereas children may be more affected by their feelings toward another child on a specific day. However, teachers may not always be aware of children's friendships outside of school and children may feel closer than their behaviour suggests. Thus, it remains possible that using peer-nomination could have resulted in different pairings and thus have yielded different findings. Finally, as previous research (e.g., Field \& Lawson, 2003; Field, Lawson, \& Banerjee, 2008) has consistently shown that schoolaged children in the UK did not have prior knowledge about the Cuscus and the Quoll, children's familiarity with these animals were not measured in the present study. Yet, it may be useful for future research to include a control question on children's familiarity about the novel animals.

As a whole, there is some indication that close friends in middle childhood influence each other's anxiety-related cognitions, as children's fear responses were correlated at baseline and became significantly more similar after a discussion about fear-related issues. Children's fearfulness after the discussion was also predicted by their friend's level of fearfulness at T1, independent of 
their own level of fearfulness at T1. Children tend to choose friends who have similar attributes to themselves (social selection) and/or become similar through interactions with each other (mutual socialization) (Hartup, 1996). Rubin, Lynch, Coplan, Rose-Krasnor and Booth (1994) supported this similarity-attraction hypothesis by demonstrating that children who were initially strangers to each other chose partners who were more similar in their sociability and the cognitive maturity of their play, and interacted more frequently with partners than non-partners. Following this reasoning, children in the present study may have become close friends because they share similar attributes with each other, including their fear-related cognitions. Alternatively, children who are close friends might shape each others' cognitions. Or indeed, children may initially become friends because they are similar and this similarity could be maintained or increased over time through their daily interactions. Longitudinal research is required to tease apart these possibilities.

Regarding the clinical implications of the findings, the results provide some indication that children may affect each other's fears but the effect appears to be relatively small. It therefore seems likely that other sources of influence, such as parents, may play a considerably larger role in affecting children's fears and this should be reflected in approaches to treatment. Nevertheless, the findings indicate that close friends may share negative cognitions and to some extent may maintain those cognitions. To our knowledge, there is no evidence regarding the extent to which primary school-aged children discuss fear-related issues with each other on a day-to-day basis, however, there is evidence that they discuss personal problems and that this can have a negative effect on anxiety; children who engaged in excessive discussions about personal problems with a friend showed higher levels of anxiety symptoms over a 6-month period (Rose, 2002; Rose, Carlson, \& Waller, 2007). Thus, it may be beneficial to ask children being treated for anxiety disorders to identify whether they have friends who may be influencing or maintaining their negative cognitions, and it may subsequently be useful for them to be given strategies for how to discuss these cognitions with peers in an adaptive way. 
Group-based CBT programs such as the 'Coping Cat' and 'Cool Kids' programs (Kendall \& Hedtke, 2006; Lyneham, Abbott, Wignall, \& Rapee, 2003) have been shown to successfully treat anxiety disorders in children (e.g., Kendall, 1994; Kendall et al., 1997; Hudson et al., 2009; Arendt, Thastum, \& Hougaard, 2016). The present finding that children's fear-related cognitions don't become more negative when children discuss their fears with more anxious peers supports the use of group therapy and may be useful information for parents concerned that exposure to more anxious children within group-based therapy may increase their child's anxiety. The present research could be extended using a cognitive bias modification (CBM) methodology (e.g., Mathews, Ridgeway, Cook, \& Yiend, 2007; Wilson, MacLeod, Mathews, \& Rutherford, 2006) asking close friends to discuss fear beliefs or ambiguous situations in a non-threatening manner over successive sessions. If this non-threat CBM training between close friends is effective in decreasing anxietyrelated cognitions and/or anxiety in children, research of this nature could inform prevention or treatment efforts. For instance, school-based interventions aiming to reduce anxiety in primary school-aged children could instruct pairs of close friends to discuss and resolve their worries in a positive manner with each other.

\section{Acknowledgements}

We would like to thank Mark Adams and Dee Kirk for their support in this research and for allowing access to the participants. Thanks also to Tracey Waters for co-ordinating the sessions, and to all the teachers, staff and participating children in the school for their contribution to this research. Finally, special thanks to Victoria Marriott and Verity Sinclair for their assistance in data collection. 


\section{References}

Arendt, K., Thastum, M., \& Hougaard, E. (2016). Efficacy of a Danish version of the Cool Kids program: a randomized wait-list controlled trial. Acta Psychiatrica Scandinavica, 133(2), 109121.

Barrett, P. (2005). FRIENDS for Life: Group leaders' manual for children. Barrett Research Resources Pty Ltd.

Barrett, P. M., Rapee, R. M., Dadds, M. M., \& Ryan, S. M. (1996). Family enhancement of cognitive style in anxious and aggressive children. Journal of Abnormal Child Psychology, 24(2), 187203.

Bauer, D. H. (1976). An exploratory study of developmental changes in children's fears. Journal of Child Psychology and Psychiatry, 17, 69-74.

Bögels, S. M., van Dongen, L., \& Muris, P. (2003). Family influences on dysfunctional thinking in anxious children. Infant and Child Development, 12(3), 243-252. doi:10.1002/icd.288

Chorpita, B. F., \& Albano, A. M. (1996). Cognitive processing in children: Relation to anxiety and family influences. Journal of Clinical Child Psychology, 25(2), 170.

Cohen, J. (1988). Statistical power analysis for the behavioural sciences. Lawrence Earlbaum Associates.: Hillsdale, New Jersey.

Costello, E. J., Egger, H. L., Copeland, W., Erkanli, A., \& Angold, A. (2011). The developmental epidemiology of anxiety disorders: Phenomenology, prevalence, and comorbidity. In W. K. Silverman \& A. P. Field (Eds.), Anxiety Disorders in Children and Adolescents (2nd ed., pp. 5675). New York: Cambridge University Press.

Creswell, C., \& O'Connor, T. G. (2006). Anxious cognitions in children: An exploration of associations and mediators. British Journal of Developmental Psychology, 24(4), 761-766. doi:10.1348/026151005x70418 
Creswell, C., O'Connor, T. G., \& Brewin, C. R. (2006). A longitudinal investigation of maternal and child 'anxious cognitions'. Cognitive Therapy and Research, 30(2), 135-147. doi:10.1007/s10608-006-9021-1

Creswell, C., Schniering, C. A., \& Rapee, R. M. (2005). Threat interpretation in anxious children and their mothers: comparison with nonclinical children and the effects of treatment. Behaviour Research and Therapy, 43(10), 1375-1381.

Creswell, C., Shildrick, S., \& Field, A. P. (2011). Interpretation of Ambiguity in Children: A Prospective Study of Associations With Anxiety and Parental Interpretations. Journal of Child and Family Studies, 20(2), 240-250. doi:10.1007/s10826-010-9390-7

Dadds, M., Barrett, P., Rapee, R., \& Ryan, S. (1996). Family process and child anxiety and aggression: An observational analysis. Journal of Abnormal Child Psychology, 24(6), 715-734. doi:10.1007/bf01664736

Dalrymple-Alford, S., \& Salmon, K. (2013). Ambiguous Information and the Verbal Information Pathway to Fear in Children. Journal of Child and Family Studies, 1-8. doi:10.1007/s10826013-9878-z

Department for Education. (2013). Statistical First Release: Schools, Pupils, and their Characteristics January 2013. Retrieved from https://www.gov.uk/government/uploads/system/uploads/attachment_data/file/207670/ Main_text-_SFR21_2013.pdf

Dodd, H. F., Stuijfzand, S., Morris, T., \& Hudson, J. L. (2015). Child Anxiety and the Processing of Ambiguity. Cognitive Therapy and Research, 1-9.

Drake, K., \& Ginsburg, G. (2012). Family Factors in the Development, Treatment, and Prevention of Childhood Anxiety Disorders. Clinical Child and Family Psychology Review (Preprints), 1-19.

Eley, T. C., \& Gregory, A. M. (2004). Behavioral genetics. In T. L. Morris \& J. S. March (Eds.), Anxiety disorders in children and adolescents (pp. 71-97). New York: Guilford.

Field, A. P. (2013). Discovering statistics using IBM SPSS statistics. Sage. 
Field, A. P. (2006). Watch Out for the Beast: Fear Information and Attentional Bias in Children. Journal of Clinical Child \& Adolescent Psychology, 35(3), 431-439. doi:10.1207/s15374424jccp3503_8

Field, A. P., Argyris, N. G., \& Knowles, K. A. (2001). Who's afraid of the big bad wolf: a prospective paradigm to test Rachman's indirect pathways in children. Behaviour Research and Therapy, 39(11), 1259-1276. doi:http://dx.doi.org/10.1016/\$0005-7967(00)00080-2

Field, Z., \& Field, A. P. (2013). How Anxiety, Interpretation Bias and Memory Affect Acquired Fear in Children Learning About New Animals. Emotion, No Pagination Specified. doi:10.1037/a0031147

Field, A. P., \& Lawson, J. (2003). Fear information and the development of fears during childhood: effects on implicit fear responses and behavioural avoidance. Behaviour Research and Therapy, 41(11), 1277-1293. doi:10.1016/s0005-7967(03)00034-2

Field, A. P., Lawson, J., \& Banerjee, R. (2008). The verbal threat information pathway to fear in children: the longitudinal effects on fear cognitions and the immediate effects on avoidance behavior. Journal of Abnormal Psychology,117(1), 214.

Field, A. P., \& Lester, K. J. (2010). Is there room for 'development' in developmental models of information processing biases to threat in children and adolescents? Clinical Child and Family Psychology Review, 13(4), 315-332. doi:10.1007/s10567-010-0078-8

Field, A. P., \& Storksen-Coulson, H. (2007). The interaction of pathways to fear in childhood anxiety: A preliminary study. Behaviour Research and Therapy, 45(12), 3051-3059. doi:http://dx.doi.org/10.1016/j.brat.2007.09.001

Freeman, K., Hadwin, J. A., \& Halligan, S. L. (2011). An experimental investigation of peer influences on adolescent hostile attributions. Journal of Clinical Child \& Adolescent Psychology, 40(6), 897-903. 
Gifford, S., Reynolds, S., Bell, S., \& Wilson, C. (2008). Threat interpretation bias in anxious children and their mothers. Cognition \& Emotion, 22(3), 497-508. doi:10.1080/02699930801886649

Ginsburg, G. S., \& Silverman, W. K. (2000). Gender role orientation and fearfulness in children with anxiety disorders. Journal of Anxiety Disorders, 14(1), 57-67.

Gullone, E. (2000). The development of normal fear: A century of research. Clinical Psychology Review, 20(4), 429-451. doi:http://dx.doi.org/10.1016/S0272-7358(99)00034-3

Hadwin, J. A., Frost, S., French, C., \& Richards, A. (1997). Cognitive processing and trait anxiety in typically developing children: Evidence for an interpretation bias. Journal of Abnormal Psychology, 106(3), 486-490.

Hadwin, J. A., Garner, M., \& Perez-Olivas, G. (2006). The development of information processing biases in childhood anxiety: A review and exploration of its origins in parenting. Clinical Psychology Review, 26(7), 876-894. doi:10.1016/j.cpr.2005.09.004

Haeffel, G. J., \& Hames, J. L. (2014). Cognitive vulnerability to depression can be contagious. Clinical Psychological Science, 2(1), 75-85.

Hartup, W. W. (1996). The company they keep: Friendships and their developmental significance. Child Development, 67(1), 1-13.

Hudson, J. L., Rapee, R. M., Deveney, C., Schniering, C. A., Lyneham, H. J., \& Bovopoulos, N. (2009). Cognitive-behavioral treatment versus an active control for children and adolescents with anxiety disorders: a randomized trial. Journal of the American Academy of Child \& Adolescent Psychiatry,48(5), 533-544.

Kelly, V. L., Barker, H., Field, A. P., Wilson, C., \& Reynolds, S. (2010). Can Rachman's indirect pathways be used to un-learn fear? A prospective paradigm to test whether children's fears can be reduced using positive information and modelling a non-anxious response. Behaviour Research and Therapy, 48(2), 164-170.

Kendall, P. C. (1994). Treating anxiety disorders in children: results of a randomized clinical trial. Journal of Consulting and Clinical Psychology, 62(1), 100. 
Kendall, P. C., Flannery-Schroeder, E., Panichelli-Mindel, S. M., Southam-Gerow, M., Henin, A., \& Warman, M. (1997). Therapy for youths with anxiety disorders: A second randomized clincal trial. Journal of Consulting and Clinical Psychology, 65(3), 366.

Kendall, P. C., \& Hedtke, K. A. (2006). Cognitive-behavioral therapy for anxious children: Therapist manual. Workbook Pub.

Kenny, D. A., Kashy, D. A., \& Cook, W. L. (2006). Dyadic data analysis. Guilford Press.

Laird, R. D., \& De Los Reyes, A. (2013). Testing informant discrepancies as predictors of early adolescent psychopathology: Why difference scores cannot tell you what you want to know and how polynomial regression may. Journal of Abnormal Child Psychology, 41(1), 1-14.

Laird, R. D., \& Weems, C. F. (2011). The equivalence of regression models using difference scores and models using separate scores for each informant: Implications for the study of informant discrepancies. Psychological Assessment, 23(2), 388.

Lang, P. J. (1968). Fear reduction and fear behaviour: Problems in treating a construct. In J. M. Schlien (Ed.), Research in Psychotherapy (Vol. 3, pp. 90-103). Washington, DC: American Psychological Association.

Lang, P. J. (1985). The cognitive psychopathology of emotion: Fear and anxiety. In A. H. Tuma \& J. D. Maser (Eds.), Anxiety and the Anxiety Disorders (pp. 131-170). Hillsdale, NJ: Erlbaum.

Lau, J. Y., Pettit, E., \& Creswell, C. (2013). Reducing children's social anxiety symptoms: Exploring a novel parent-administered cognitive bias modification training intervention. Behaviour Research and Therapy, 51(7), 333-337.

Lyneham, H. J., Abbott, M. J., Wignall, A., \& Rapee, R. M. (2003). The cool kids anxiety treatment program. Sydney: MUARU, Macquarie University.

Mathews, A., Ridgeway, V., Cook, E., \& Yiend, J. (2007). Inducing a benign interpretational bias reduces trait anxiety. Journal of Behavior Therapy and Experimental Psychiatry, 38(2), 225236. 
Muris, P., \& Field, A. P. (2010). The Role of Verbal Threat Information in the Development of Childhood Fear. "Beware the Jabberwock!". Clinical Child and Family Psychology Review, 13(2), 129-150.

Muris, P., Meesters, C., \& Knoops, M. (2005). The relation between gender role orientation and fear and anxiety in nonclinic-referred children. Journal of Clinical Child and Adolescent Psychology, 34(2), 326-332.

Muris, P., \& Rijkee, S. (2011). Facing the beast apart together: Fear in boys and girls after processing information about novel animals individually or in a duo. Journal of Child and Family Studies, 20(5), 554-559.

Muris, P., Rassin, E., Mayer, B., Smeets, G., Huijding, J., Remmerswaal, D., \& Field, A. P. (2009). Effects of verbal information on fear-related reasoning biases in children. Behaviour Research and Therapy, 47, 206-214.

Ollendick, T., Yang, B., Dong, Q., Xia, Y., \& Lin, L. (1995). Perceptions of fear in other Children and adolescents: The role of gender and friendship status. Journal of Abnormal Child Psychology, 23(4), 439-452. doi:10.1007/BF01447207

Ooi, J., Dodd, H., \& Walsh, J. (2015). Shared Cognition in Childhood Anxiety: Interpretation Bias in Preschool Children and Their Parents. Journal of Child and Family Studies, 1-10. doi:10.1007/s10826-015-0143-5

Öst, L. G. (1987). Age of onset in different phobias. Journal of Abnormal Psychology, 96(3), 223-229. Palapattu, A. G., Kingery, J. N., \& Ginsburg, G. S. (2006). Gender role orientation and anxiety symptoms among African American adolescents. Journal of Abnormal Child Psychology, 34(3), 423-431.

Rachman, S. (1977). The conditioning theory of fearacquisition: A critical examination. Behaviour Research and Therapy, 15(5), 375-387. doi:http://dx.doi.org/10.1016/0005-7967(77)90041-9 
Rubin, K. H., Lynch, D., Coplan, R., Rose-Krasnor, L., \& Booth, C. L. (1994). "Birds of a feather...": Behavioral concordances and preferential personal attraction in children. Child Development, 65(6), 1778-1785.

Rose, A. J. (2002). Co-rumination in the friendships of girls and boys. Child Development, 73(6), 1830-1843.

Rose, A. J., Carlson, W., \& Waller, E. M. (2007). Prospective associations of co-rumination with friendship and emotional adjustment: Considering the socioemotional trade-offs of corumination. Developmental Psychology, 43(4), 1019.

Schunk, D. H. (1987). Peer models and children's behavioral change. Review of Educational Research, 57(2), 149-174.

Schunk, D. H., \& Hanson, A. R. (1985). Peer models: Influence on children's self-efficacy and achievement. Journal of Educational Psychology, 77(3), 313.

Spence, S. H. (1997). Structure of anxiety symptoms among children: A confirmatory factor-analytic study. Journal of Abnormal Psychology, 106(2), 280-297. doi:10.1037/0021-843X.106.2.280 Spence, S. H. (1998). A measure of anxiety symptoms among children. Behaviour Research and Therapy, 36(5), 545-566. doi:http://dx.doi.org/10.1016/S0005-7967(98)00034-5

Wilson, E. J., MacLeod, C., Mathews, A., \& Rutherford, E. M. (2006). The causal role of interpretive bias in anxiety reactivity. Journal of Abnormal Psychology, 115(1), 103. 


\section{Appendix A}

The Nature Reserve Map
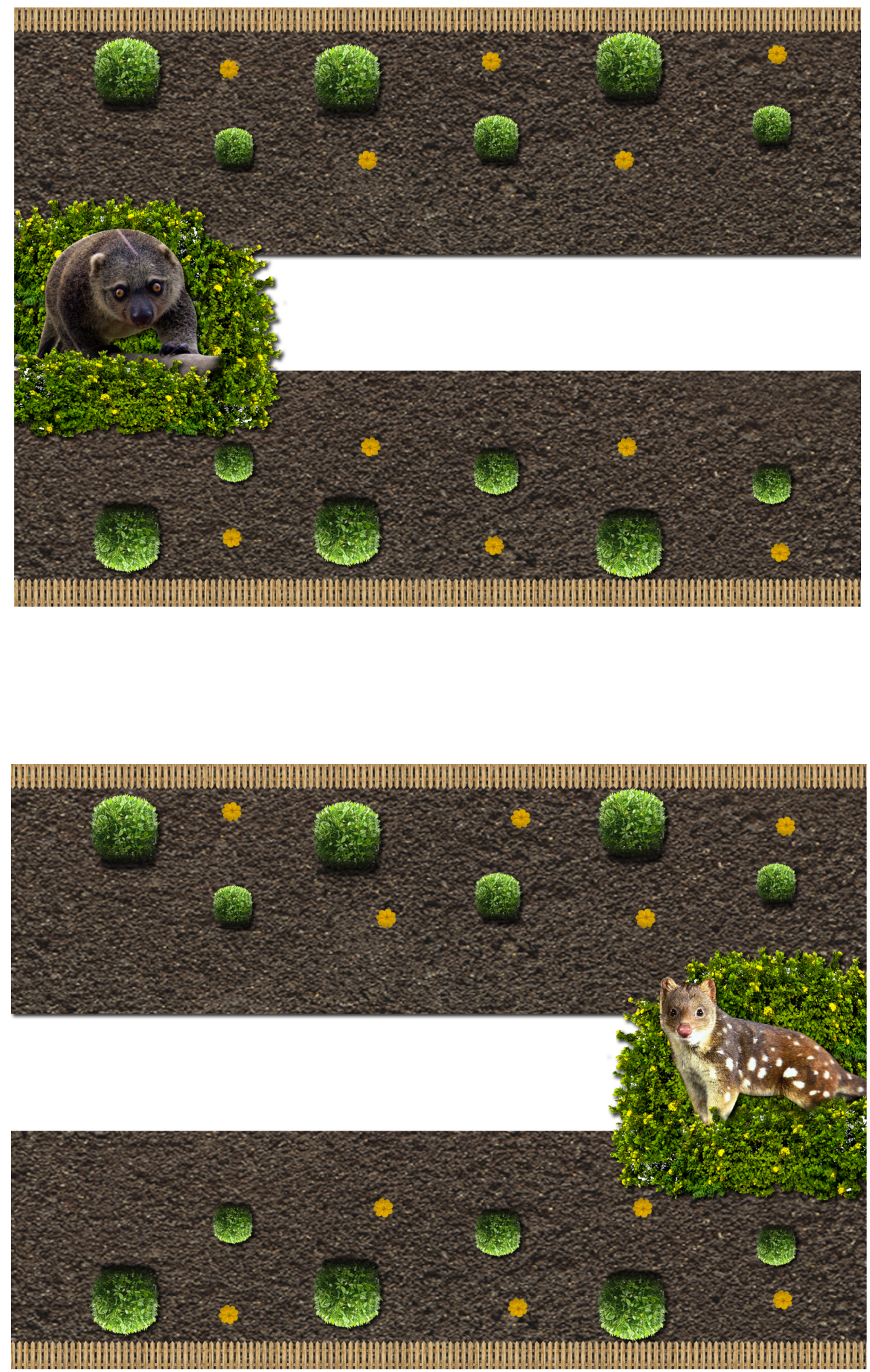
Table 1

Descriptive Statistics for Verbal Information Transfer

Mean (Standard Deviation)

\begin{tabular}{|c|c|c|c|c|c|c|}
\hline \multirow[b]{2}{*}{ FBQ Ambiguous T1 } & \multicolumn{2}{|c|}{ Entire Sample } & \multicolumn{2}{|c|}{ Boys } & \multicolumn{2}{|c|}{ Girls } \\
\hline & 26.91 & $(10.26)$ & 23.74 & (9.73) & 29.37 & $(10.02)$ \\
\hline FBQ Threat T1 & 42.55 & (9.96) & 40.21 & $(11.63)$ & 44.38 & $(8.02)$ \\
\hline NRM Ambiguous T1 & 6.34 & (5.66) & 4.83 & $(5.05)$ & 7.51 & $(5.85)$ \\
\hline NRM Threat T1 & 12.87 & (5.53) & 11.32 & (6.41) & 14.07 & $(4.40)$ \\
\hline
\end{tabular}

Note. $F B Q$ fear beliefs questionnaire, NRM nature reserve map. 
Table 2

Analyses for Verbal Information Transfer

\begin{tabular}{|c|c|c|c|c|}
\hline & \multicolumn{4}{|l|}{ Main/ Interaction } \\
\hline & Effects & $F$ & $d f$ & partial $\eta 2$ \\
\hline \multirow[t]{7}{*}{ Fear Beliefs } & Info Type & $19.92 * *$ & $(1,236)$ & .08 \\
\hline & Gender & $5.48 *$ & $(1,236)$ & .02 \\
\hline & Anxiety & $60.20 * *$ & $(1,236)$ & .2 \\
\hline & Age & 1.90 & $(1,236)$ & .01 \\
\hline & Info Type x Anxiety & $14.11 * *$ & $(1,236)$ & .06 \\
\hline & Info Type x Age & 1.45 & $(1,236)$ & .01 \\
\hline & Info Type x Gender & .12 & $(1,236)$ & $<.001$ \\
\hline \multicolumn{5}{|l|}{ Behavioural } \\
\hline \multirow[t]{7}{*}{ Avoidance } & Info Type & .93 & $(1,236)$ & $<.004$ \\
\hline & Gender & $9.40 * *$ & $(1,236)$ & .04 \\
\hline & Anxiety & $24.42 * *$ & $(1,236)$ & .09 \\
\hline & Age & $12.20 * *$ & $(1,236)$ & .05 \\
\hline & Info Type x Anxiety & 2.37 & $(1,236)$ & .01 \\
\hline & Info Type x Age & 1.35 & $(1,236)$ & .01 \\
\hline & Info Type x Gender & .49 & $(1,236)$ & $<.005$ \\
\hline
\end{tabular}

\footnotetext{
* Are significant at $\mathrm{p}<.05 .{ }^{* *}$ Are significant at $\mathrm{p}<.01$.
}

Note: Effect size magnitudes for partial $\eta^{2}$ (Cohen, 1988): 0.01 (small), 0.06 (medium), and 0.14 (large). 
Table 3

Bootstrapped Pearson's Correlations for the Fear Responses Between Close Friends, and the ZStatistics Comparing Correlations from T1 to T2

\begin{tabular}{|c|c|c|c|c|c|c|c|c|c|c|}
\hline & & \multicolumn{2}{|c|}{$\begin{array}{l}\text { Ambiguous } \\
\text { Fear Beliefs }\end{array}$} & \multicolumn{2}{|c|}{$\begin{array}{l}\text { Threatening } \\
\text { Fear Beliefs }\end{array}$} & \multicolumn{2}{|c|}{$\begin{array}{l}\text { Ambiguous } \\
\text { Avoidance }\end{array}$} & \multicolumn{2}{|c|}{$\begin{array}{c}\text { Threatening } \\
\text { Avoidance }\end{array}$} & \multirow[t]{2}{*}{$\begin{array}{l}\text { T1 vs. T2 } \\
\text { Z-Statistics }\end{array}$} \\
\hline & & $\mathrm{T} 1$ & $\mathrm{~T} 2$ & $\mathrm{~T} 1$ & $\mathrm{~T} 2$ & $\mathrm{~T} 1$ & $\mathrm{~T} 2$ & $\mathrm{~T} 1$ & $\mathrm{~T} 2$ & \\
\hline $\begin{array}{l}\text { Ambiguous } \\
\text { Fear Beliefs }\end{array}$ & $\begin{array}{l}\mathrm{T} 1 \\
\mathrm{~T} 2\end{array}$ & $.28 * *$ & $.53 * *$ & & & & & & & $|z|=2.70 * *$ \\
\hline $\begin{array}{l}\text { Threatening } \\
\text { Fear Beliefs }\end{array}$ & $\mathrm{T} 1$ & & & $.33^{* *}$ & $.57 * *$ & & & & & $|z|=3.12 * *$ \\
\hline $\begin{array}{l}\text { Ambiguous } \\
\text { Avoidance }\end{array}$ & $\begin{array}{l}\mathrm{T} 1 \\
\mathrm{~T} 2\end{array}$ & & & & & $.33 * *$ & $.48 * *$ & & & $|z|=2.04 *$ \\
\hline $\begin{array}{l}\text { Threatening } \\
\text { Avoidance }\end{array}$ & $\mathrm{T} 1$ & & & & & & & $.23^{*}$ & $.46^{* *}$ & $|z|=2.20 *$ \\
\hline
\end{tabular}

* Are significant at $p<.05 .{ }^{* *}$ Are significant at $p<.01$. 